\title{
Electrochemical in-situ studies of solar mediated oxygen transport and turnover dynamics in a tree trunk of Tilia cordata
}

\author{
Christian Tötzke ${ }^{(1-2)}$, \\ Jan Cermak ${ }^{(3)}$ \\ Nadezhda Nadezhdina ${ }^{(3)}$, \\ Helmut Tributsch ${ }^{(1-4)}$
}

\begin{abstract}
Platinum electrodes were implanted into the xylem of a lime tree (Tilia cordata) stem and solar-induced electrochemical potential differences of up to $120 \mathrm{mV}$ were measured during the vegetative period and up to $30 \mathrm{mV}$ in winter. The time dependent curves were found to be delayed with respect to solar radiation, sap flow activity, temperature and vapor pressure deficit. A general equation for the potential difference was derived and simplified by analyzing the effect of temperature and tensile strength. The potential determining influence of oxygen concentration on the respective location of the platinum electrode was identified as the principal phenomenon measured. A systematic analysis and investigation of the observed periodic oxygen concentration signals promises new information on sap flow, oxygen diffusion through tree tissues and on oxygen consumption related to the energy turnover in tree tissues.
\end{abstract}

Keywords: Tree Stems, Oxygen Transport, Xylem, Sap Flow, Tree Metabolism, Electrical Potential

\begin{abstract}
Introduction
Water and aqueous solutions of inorganic and organic ionic and molecular species play a fundamental role in the complex behavior of trees. Electrochemical measurement techniques have demonstrated to be the most suitable tools for gaining information on the physical chemistry of liquids, but are practically not applied in tree research. Also the tensile state of water should be accessible for electrochemical research. Thermodynamic considerations on the state of water in tree trunks during transport to the tree tops suggest a difference of electrochemical potentials between different tree heights. Potential differences were actually repeatedly measured between tissues of living trees and the soil and daily and seasonal changes of the signal were observed (Fensom 1963, Toriyama 1991, Morat et al. 1994, Koppán et al. 2000, 2002, Gibert et al. 2006). For a period of 11 years, Toriyama (1991) studied electrical potentials on Al-
\end{abstract}

bizia julibrissin trees, observing daily changes in the order of $40 \mathrm{mV}$. Also seasonal changes were found. Toriyama (1991) was especially interested in understanding potential anomalies, which he observed before earthquakes. What he apparently observed was probably the effect of groundwater level changes, which should have an effect on the water supply to trees. The study of Fensom (1963) on an elm tree (Ulmus) yielded typical potential differences between 20 and $40 \mathrm{mV}$ with the highest potential difference observed in the afternoon. He observed a direct correlation between the electrical potentials and the sap flow, and assumed an electrokinetic phenomenon. However, Gibert et al. (2006) found a significant time delay between sap flow and potential signal in black poplar (Populus nigra) and, consequently, rejected the above hypothesis. The maximum sap flow clearly preceded the maximum potential difference and the potential difference continued in the eve-
(1) Helmholtz Centre Berlin for Materials und Energy HZB, 14109 Berlin (Germany); (2) Institute of Earth and Environmental Science, University of Potsdam, 14476 Potsdam (Germany); (3) Institute of Forest Botany, Dendrology and Geobiocoenology, Mendel University, 61300 Brno (Czech Republic); (4) Present address: helmut.tributsch@alice.it

@ Christian Tötzke (toetzke@uni-potsdam.de)

Received: Apr 18, 2015 - Accepted: Feb 01, 2017

Citation: Tötzke C, Cermak J, Nadezhdina N, Tributsch H (2017). Electrochemical in-situ studies of solar mediated oxygen transport and turnover dynamics in a tree trunk of Tilia cordata. iForest 10: 355-361. - doi: 10.3832/ifor1681-010 [online 0000-00-00]

Communicated by: Tamir Klein ning, when the sap flow had already ceased. They consequently assumed the potential difference to be generated by ion diffusion from the xylem sap into the xylem walls establishing a concentration gradient in charge carriers. Gibert et al. (2006) used steel electrodes in tree trunks. This type of electrodes dissolves iron ions, which become potential determining. For this reason, at least part of the potentials measured must have been caused by concentration gradients of iron. They have to be considered artificial and difficult to interpret. The same is also true for electrodes placed into the ground. They permit electron exchange with humic substances which may shift the potential in an unpredictable way. For this reason, only noble metal electrodes are expected to yield reliable information. Insertion of one of the electrodes into the ground may give information, which is difficult to interpret because of the complexity of inorganic and organic components in solutions present in the ground.

One solution could be the potential measurement of a platinum electrode in contact with xylem water of a tree against a well reproducible, easy to handle reference electrode. Such a system would be the Clark electrode with platinum as the working electrode and a $\mathrm{AgCl}$ electrode as the reference with an oxygen transparent membrane (Teflon, Cellophane) in between. The problem we found was that such a $\mathrm{AgCl}$ electrode with membrane was difficult to install in the xylem of a tree without damaging the water transporting system under negative pressure. For this reason, we decided to work with platinum electrodes at different heights at the tree 


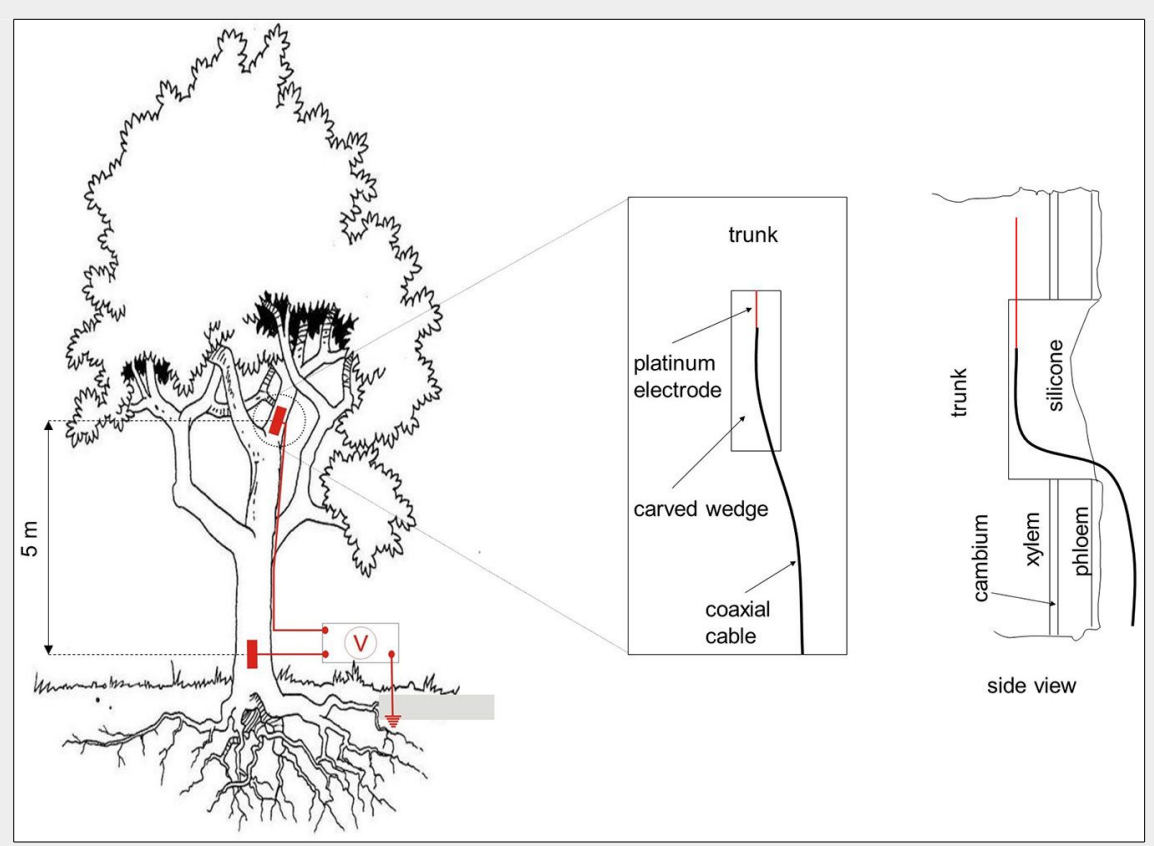

Fig. 1 - Installation scheme of the platinum electrodes measuring the electrochemical potential difference of xylem inside the trunk.

trunk. The research strategy assumed here is to use platinum electrodes to facilitate a reliable interpretation of electrical potential measurements and to place both platinum electrodes within the xylem sap environment in different height of the tree stem. In this way a gradient of water potential within the tree should be accessible and measurable. The presence of oxygen in the tree tissues should definitively be measurable and it is expected to vary in dependence of the solar-powered sap transport.

Tree sap transport, indirectly powered by solar radiation, may be a relevant additional mechanism for oxygen supply. It is well known that oxygen enters the tree via the water absorbed by the roots (Gansert 2003, Sortz \& Hietz 2006) and serves for supplying the energy infrastructure of stems. Overnight, during absence of sapflow, the oxygen present in the xylem is largely consumed by plant tissues. Such behavior was systematically studied in long term investigations of a birch (Betula pendula) tree (Burgdorf 2006). In addition, plants occasionally suffer from oxygen deficiency but developed strategies for oxygen transport and distribution.

Consequently, the aims of this study were: (1) to develop an experimental technique for studying the oxygen supply in trees and to correlate it with sap movements, and (2) to provide reliable electro-

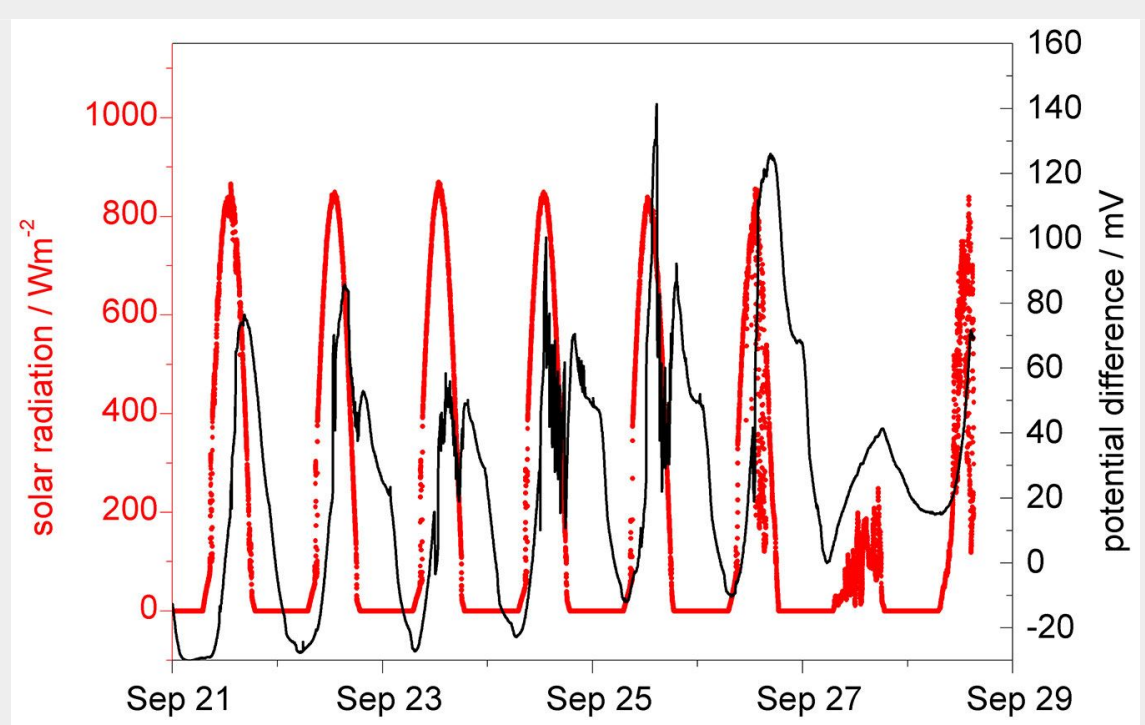

Fig. 2 - Evolution of potential difference between the two platinum electrodes in relation to solar radiation during late growing season. The tree was completely foliated. chemical potential measurements in tree trunks using platinum electrodes. These electrodes are introduced into xylem water conduits, which are expected to contain only solutions of inert inorganic ions besides of oxygen.

\section{Material and methods}

For the electrochemical potential measurements a healthy $12 \mathrm{~m}$ high small-leaved lime tree (Tilia cordata Mill.) was selected in the garden at the Lise-Meitner-campus of the Helmholtz Center Berlin for Materials and Energy. Platinum electrodes were inserted into the xylem of the tree stem, one at the basis and the second at the height of $5 \mathrm{~m}$. Structure and geometry of the contacts between platinum and the tree tissues are shown in Fig. 1. In order to facilitate a favorable electrical contact with the xylem $3 \mathrm{~cm}$ thick vertical wedges were cut into the tree bark. After introduction and fixation of the electrodes the injury was sealed with silicone adhesive. The electrodes were connected via sealed coaxial cables with a grounded voltmeter in order to record the voltage difference. A Hoiki Voltage Logger 3635-24 (Hioki E.E. Corp., Nagano, Japan) was employed with a measure range of $\pm 500 \mathrm{mV}$ and an input impedance of $1.5 \mathrm{MOhm}$.

Sap flow was measured by the heat field deformation method (Nadezhdina et al. 1998, 2004, 2012). The technique is based on the measurement of the heat field pattern evolving around a heated needle inserted into the sapwood of the tree. Changes in the heat field pattern due to the variable tree sap flow are monitored by two pairs of thermocouples, which were placed symmetrically above and below the heater and asymmetrically on one side of the heater. The ratio of measured temperature gradients is used to calculate the sap flow. Temperature differences were measured every $10 \mathrm{~s}$ and recorded every minute by a UNILOG data logger (EMS, Brno, Czech Republic). Additionally, the solar radiation data and temperature were recorded via the nearby weather station of the Helmholtz Center.

Measurements were performed during the period from August 2006 to August 2007. Data measured during both the growing season and leafless winter period were collected.

\section{Results and discussion}

At the beginning of fall, when trees still had all their leaves, a maximum potential difference of 120-130 mV was measured between the two $5 \mathrm{~m}$ distant electrodes during the period from September $20^{\text {th }}$ to $28^{\text {th }} 2006$ (Fig. 2). Patterns of diurnal changes in potential differences clearly followed those of solar radiation with some delay. In addition, the potential differences are still present in the evening well after sunset (better seen in Fig. 3). This may indicate that the potential difference is not a direct immediate consequence of solar ra- 
Fig. 3 - Better resolved section (September $26^{\text {th }}-27^{\text {th }} 2006$ ) of Fig. 2 showing the correspondence between solar radiation and electrode potential difference.

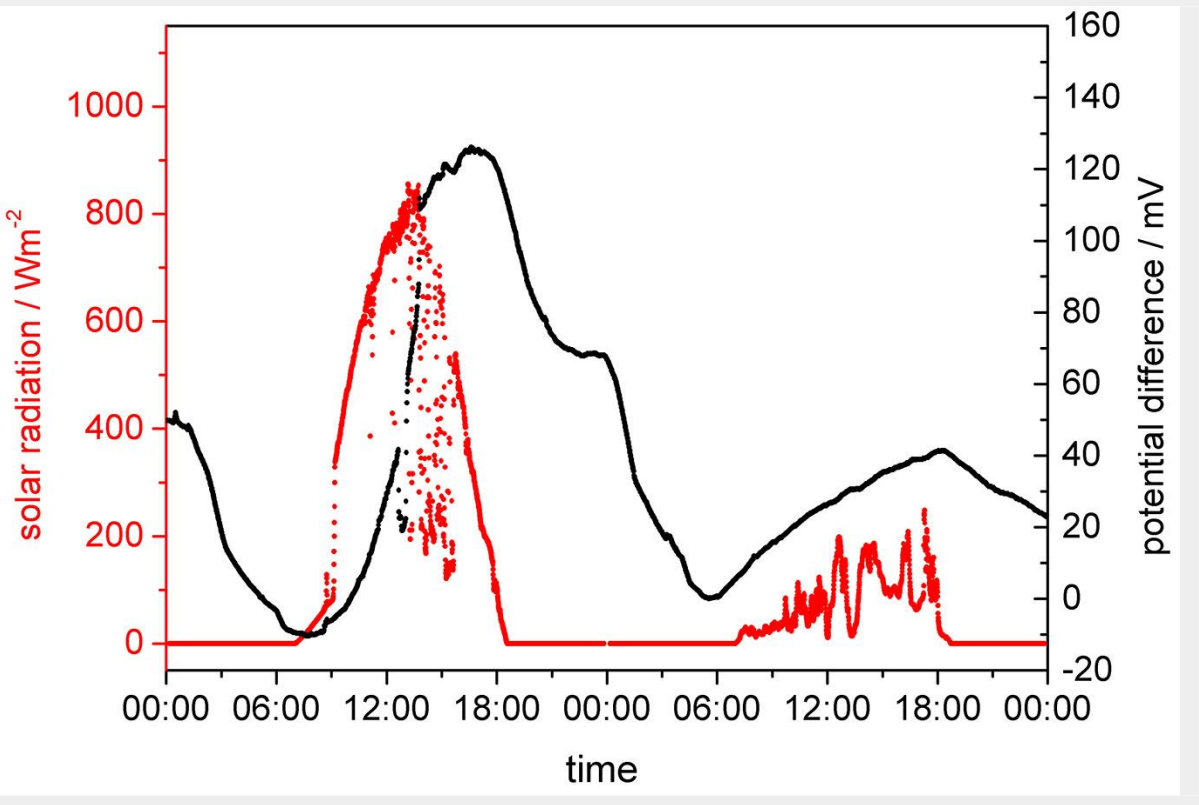

diation, but caused by another solar-triggered intermediate effect. It is well established that solar irradiation generates transpiration and water loss of trees, which, in turn, stimulates and activates sap flow in the xylem. Because of the elastic water storage system in the tree trunk, branches and leaves the sap flow on the basis of the tree only responses with a certain delay to radiation (Milne et al. 1983, Wronski et al. 1985, Zweifel \& Häsler 2001, Sevanto et al. 2002, Schulze et al. 2004, Cermák et al. 2007).

It appears reasonable to assume that the potential difference signals are correlated with the delayed sap flow, which may transport electrochemically active chemical species. A concentration difference of such electrochemically active species can generate a potential difference. However, considering the concentration difference may not be sufficient because the liquid environment may also influence the potentials.
Consequently, chemical activities should be taken into account. In addition, the negative xylem pressure, which may also changes with the tree height, may affect the activity coefficient.

Fig. 3 shows the course of solar radiation and the potential difference for a sunny followed by an overcast day. It is obvious that the measured electrochemical potential difference strongly depends on the radiation input. On the overcast day the potential difference is only one third of that of the sunny day. On September $26^{\text {th }}$ the potential difference increases with a little delay after sunrise reaching its maximum about $6 \mathrm{pm}$, i.e., with a lag of about 4 hours with respect to solar radiation. Afterwards the difference potential becomes smaller throughout the remaining day, however, is still present after sunset. The minimum is only reached shortly before sunrise. Considering the course of potential difference it appears reasonable to attribute the measured difference to different oxygen concentrations in the xylem. The concentrations at the electrodes are mainly determined by the rate of oxygen supply via the solar-mediated sap flow and the consumption by living tissue. However, the fact that not all potential difference curves are identical during comparable solar input indicates that also other parameters are determining the system. They may include different temperatures, differently controlled stomata openings, and different oxygen diffusion parameters in the tree bark.

Fig. 4 shows that also in winter in the leafless state of the tree, solar induced potential differences are still detected. However, with less than $20-30 \mathrm{mV}$ they are significantly smaller than those observed during the vegetation period. They are also less correlated with solar radiation. Their occurrence may, nevertheless, indicate that some physiological activity is still present.
Fig. 4 - Evolution of the potential difference between the two platinum electrodes in relation to solar radiation. The tree was in its non-vegetative, leafless phase.

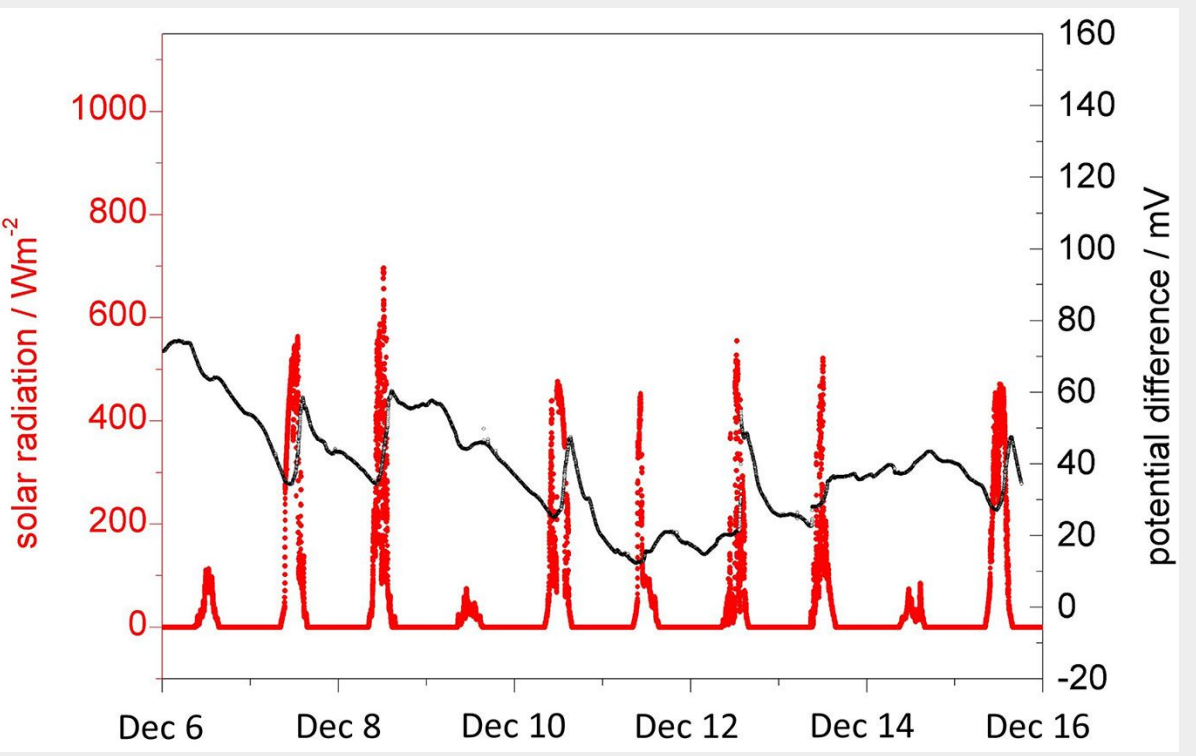




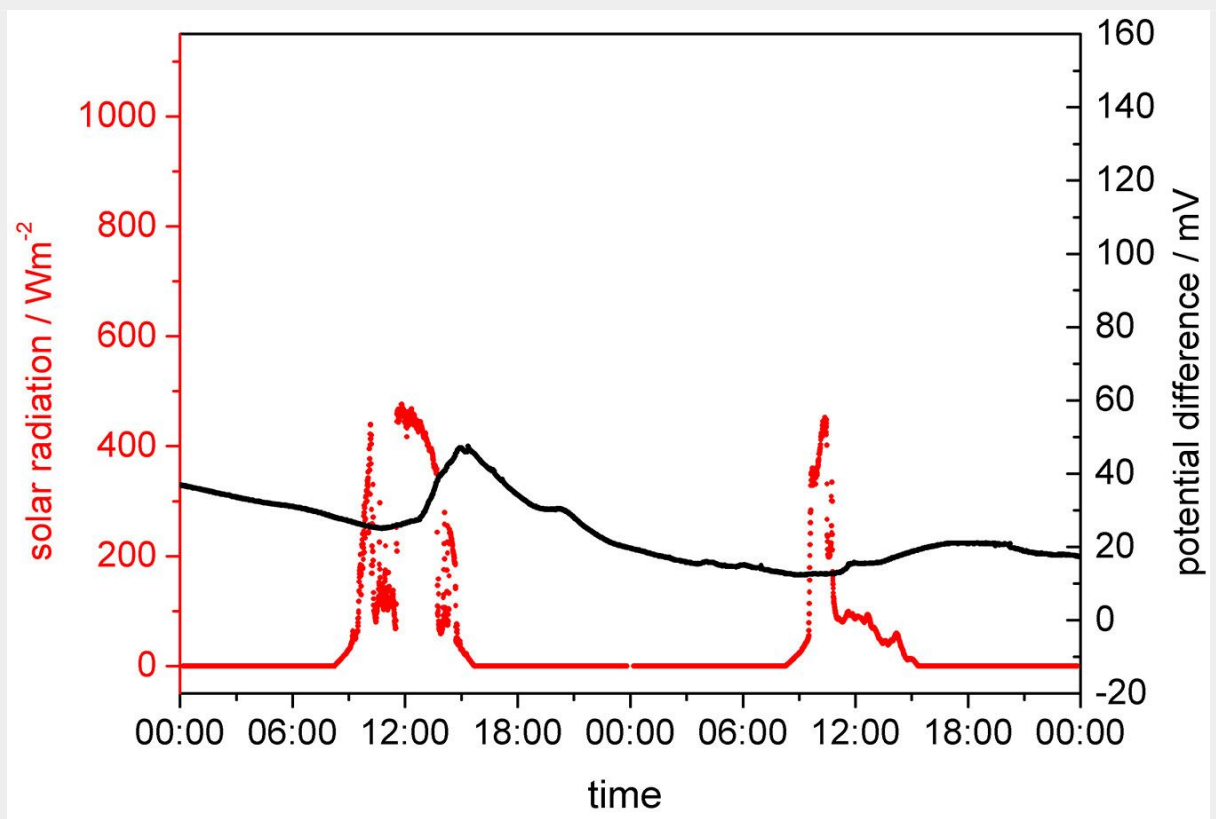

Fig. 5 - Better resolved section (December $10^{\text {th }}-11^{\text {th }} 2006$ ) of Fig. 4 (lime tree outside the vegetative period) showing the poor correspondence between solar radiation and electrode potential difference.

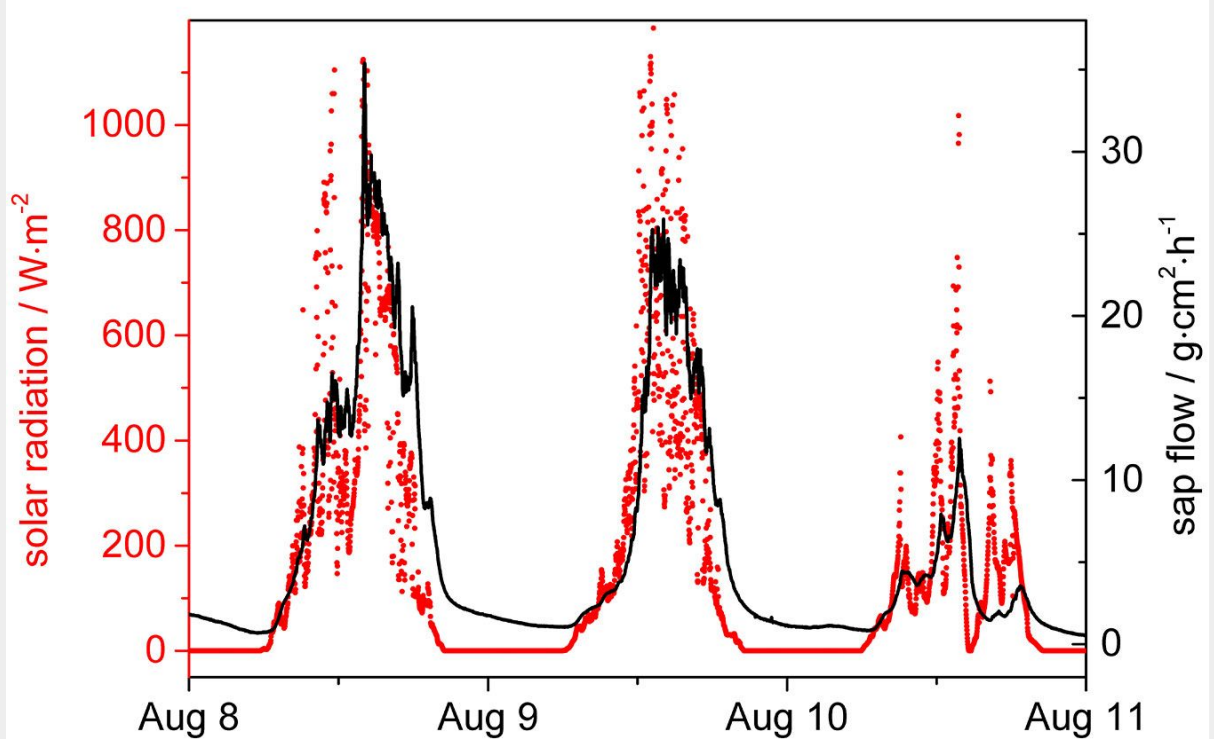

Fig. 6 - Radiation and sap flow measured in the xylem of the lime tree trunk at breast height measured during a period of three days.

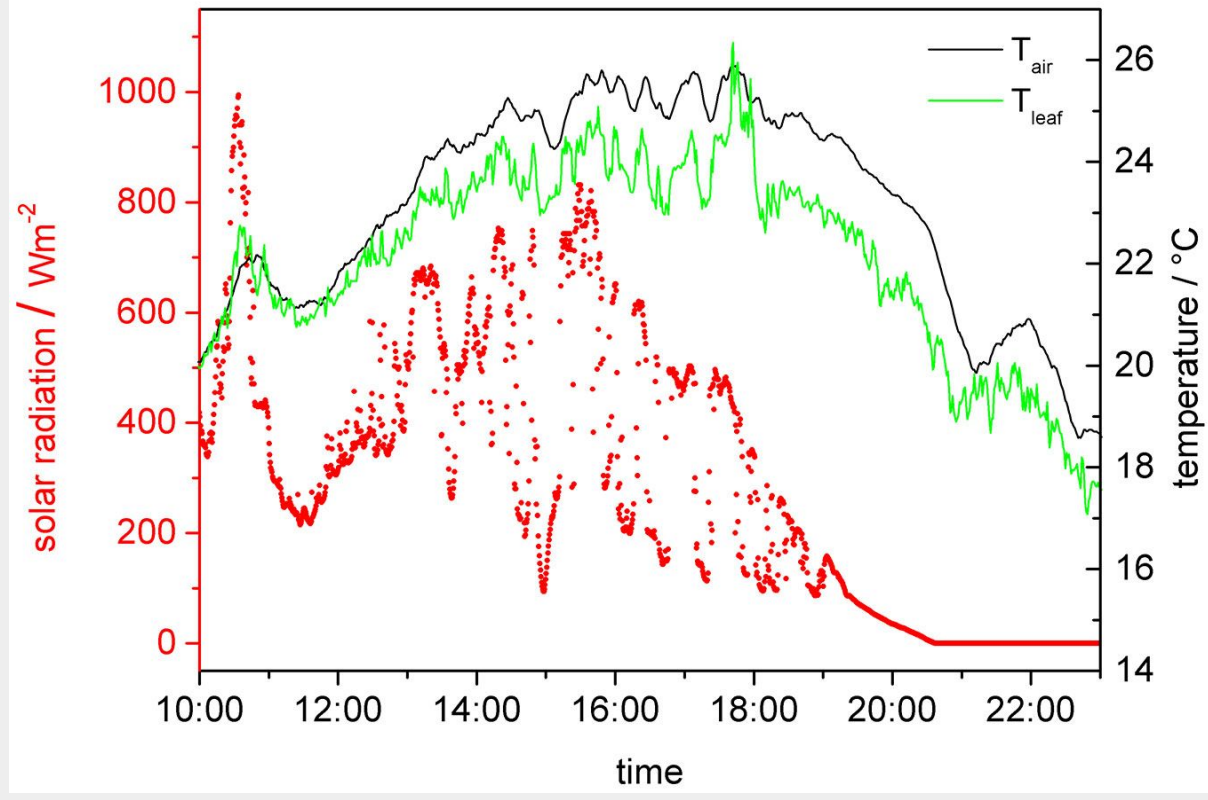

Fig. 7 - Exemplary course of air temperature $T_{\text {air, }}$ leaf temperature $T_{\text {leaf }}$ and solar radiation as measured on a sunny day (August $7^{\text {th }}$ 2006). 
The poorer correlation with solar radiation is especially seen in Fig. 5, where two subsequent days are plotted at higher resolution. Here, an inhomogeneous warming of the tree stem may have a significant influence on the development of the potential difference between the platinum electrodes.

In order to evaluate and understand the recorded potential differences, sap flow measured at breast height in the lime tree trunk is plotted along with the solar radiation (Fig. 6). The sap flow density in the lime tree essentially runs in parallel with the course of solar radiation. It is expected that the dynamics of sap flow is relevant for understanding the solar generated potential variations in trees.

Other important parameters required for the interpretation of solar radiation-related variations in the electrochemical potential are air temperature $T_{\text {air }}$ and leaf temperature $T_{\text {leaf }}$ (Fig. 7). It can be seen that air and leaf temperatures essentially coincide and that the total temperature fluctuation during a sunny day was not more than $7^{\circ} \mathrm{C}$.

The periodic potential differences observed in the tree trunk of Tilia cordata are expected to be caused by a difference in chemical activity $a$. Chemical activity is proportional to the concentration $c$, with $\gamma$ being the activity coefficient. What species could be measured in terms of concentration? In the potential range concerned during measurements $\mathrm{Ca}^{2+}, \mathrm{Na}^{+}, \mathrm{K}^{+}, \mathrm{Mg}^{2+}, \mathrm{SO}_{4}{ }^{2-}$, $\mathrm{PO}_{4}^{3-}, \mathrm{Cl}^{3}, \mathrm{NO}_{3}$, which are all solved in the apoplastic fluid, are not electrochemically active. Molecular oxygen, however, is dissolved in the sap water and is also electrochemically very active (Del Hierro et al. 2002, Gansert 2003, Spicer \& Holbrook 2005, Burgdorf 2006, Sortz \& Hietz 2006 ). Its behavior at electrodes is well studied and additional water species involved in the reactions concerned either in slightly alkaline or acidic water are $\mathrm{H}_{2} \mathrm{O}, \mathrm{OH}^{\text {, }}$, and $\mathrm{H}^{+}$. Dissolved oxygen can have different activity depending on the molecular structure of the solvent. Water in the xylem of a transpiring tree is frequently subjected to large negative pressure turning its molecular structure into a tensile state. This state is characterized by additional hydrogen bonding (Szabó et al. 2008). Due to the pressure gradient along the xylem the activity of oxygen in tensile water may be different at different height of the tree trunk. This is a significant challenge for the present study and has to be analyzed in detail.

\section{Theoretical considerations}

In order to understand the development of electrochemical potential differences between two platinum electrodes inserted at the bottom and at $5 \mathrm{~m}$ height of a lime tree stem, respectively, their possible complex electrochemical behavior has to be calculated and evaluated. The $\mathrm{pH}$ value in plant cells typically varies between $\mathrm{pH}=6.5$ and $\mathrm{pH}=7.5$. It is well known that oxygen reacts differently in acid and basic environ- ment. In nearly neutral $\mathrm{pH}$ region it is therefore reasonable to consider both reaction possibilities.

Acid water (eqn. 1):

$$
2 \mathrm{H}_{2} \mathrm{O} \leftrightarrow \mathrm{O}_{2}+4 \mathrm{H}^{+}+4 e^{-}
$$

The electrode potential according to the Nernst equation is (eqn. 2):

$$
E_{\mathrm{O}_{2}}=E_{\mathrm{O}_{2}}^{0}+\frac{R T}{z F} \ln \frac{a_{\mathrm{O}_{2}} a_{H^{+}}^{4}}{a_{\mathrm{H}_{2} \mathrm{O}}^{2}}
$$

$R$ denotes the universal gas constant, $T$ the temperature, $z$ the number of formally transferred charges, and $F$ the Faraday constant. $a$ denotes the activity: $a=\gamma c$ which is proportional to the concentration $c(\gamma=$ activity coefficient $)$ of oxygen, water and protons, respectively. When inserting $z$ $=4$, considering a standard temperature at $25^{\circ} \mathrm{C}$, and changing to a decade logarithm the eqn. 2 yields the electrode potential in Volt (eqn. 3):

$$
E_{\mathrm{O}_{2}}=1.23+\frac{0.059}{4} \log \frac{a_{\mathrm{O}_{2}} a_{\mathrm{H}^{+}}^{4}}{a_{\mathrm{H}_{2} \mathrm{O}}^{2}}
$$

This formula can now be rewritten, considering $\log a_{\mathrm{H}^{+}}=\mathrm{pH}$, the $\mathrm{pH}$ value of the water (eqn. 4):

$$
\begin{aligned}
E_{\mathrm{O}_{2}} & =1.23+0.0147 \log a_{\mathrm{O}_{2}} \\
& -0.059 \mathrm{pH}-0.029 a_{\mathrm{H}_{2} \mathrm{O}}
\end{aligned}
$$

A similar derivation can now be made for alkaline water, where the following reaction is expected to proceed (eqn. 5):

$$
4 \mathrm{OH}^{-} \leftrightarrow \mathrm{O}_{2}+2 \mathrm{H}_{2} \mathrm{O}+4 e^{-}
$$

Its Nernst equation is (eqn. 6):

$$
E_{\mathrm{O}_{2}}=E_{\mathrm{O}_{2}}^{0}+\frac{R T}{z F} \ln \frac{a_{\mathrm{O}_{2}} a_{\mathrm{H}_{2} \mathrm{O}}^{2}}{a_{\mathrm{OH}}^{4}}
$$

and, when it is rewritten for decade logarithm and for a temperature of $\mathrm{T}=25^{\circ} \mathrm{C}$ (eqn. 7):

$$
E_{\mathrm{O}_{2}}=0.401+\frac{0.059}{4} \log \frac{a_{\mathrm{O}_{2}} a_{\mathrm{H}_{2} \mathrm{O}}^{2}}{a_{\mathrm{OH}}^{4}}
$$

from which follows (eqn. 8):

$$
\begin{aligned}
E_{\mathrm{O}_{2}} & =0.401+0.0147 \log a_{\mathrm{O}_{2}} \\
& +0.029 \log a_{\mathrm{H}_{2} \mathrm{O}}-0.059 \log a_{\mathrm{OH}^{-}}
\end{aligned}
$$

Considering that $\log a_{\mathrm{OH}^{-}}=-14+\mathrm{pH}$, we obtain (eqn. 9):

$$
\begin{aligned}
E_{\mathrm{O}_{2}}^{\prime} & =1.23+0.0147 \log a_{\mathrm{O}_{2}} \\
& +0.059 \mathrm{pH}+0.029 \log a_{\mathrm{H}_{2} \mathrm{O}}
\end{aligned}
$$

When the oxygen electrode potential of relation for acid solution (eqn. 4) and electrode reaction (eqn. 1) is compared with the oxygen electrode potential in basic solution (eqn. 8) and electrode reaction (eqn. 5), it can be seen that they are essentially identical with the exception of the last term, which contains the water activity $a_{\mathrm{H} 2 \mathrm{O}}$. Water at ambient pressure and $25^{\circ} \mathrm{C}$ is yielding the activity 1 , from which follows that the third term would be identical to zero. This can, however, not be assumed for water in an actively water pumping tree. The sap water in the xylem would be under negative pressure. The reversible thermodynamic derivation of the formalism expressed in the third terms of eqn. 4 and eqn. 8 does not consider negative activity and $\log a_{\mathrm{H} 2 \mathrm{O}}$ is not defined for such conditions. An irreversible thermodynamic theory for tensile water properties must finally replace this third term. A step in this direction has been undertaken by considering the tensile state of water as a dynamically self-organized state of water as a consequence of evaporative solar energy activity (Tributsch et al. 2005).

We can formally replace this third term by tensile water activity, which should depend on the value of the negative water activity $\left(-a_{\mathrm{H} 2 \mathrm{O}}\right)$ and the $\mathrm{pH}: b \log a_{\mathrm{t}}^{\prime}\left(\mathrm{pH},-a_{\mathrm{H} 2 \mathrm{O}}\right)$.

The generalized relation for the oxygen potential $E_{\mathrm{O}_{2}}^{\prime}$ reads then in Volt (eqn. 10):

$$
\begin{aligned}
E_{\mathrm{O}_{2}}^{\prime} & =1.23+0.0147 \log a_{\mathrm{O}_{2}} \\
& +0.059 \mathrm{pH}+b \log a_{t}^{\prime}\left(p H,-a_{\mathrm{H}_{2} \mathrm{O}}\right)
\end{aligned}
$$

We calculate now the difference, in oxygen electrode potential, measured between the upper $\left(E_{\mathrm{O}_{2}}^{\prime}\right)$ and the lower platinum electrodes $\left(E_{\mathrm{O}_{2}}\right)$, inserted into the lime tree's water carrying xylem structure ( $c$ is a new proportionality constant - eqn. 11):

$$
\begin{aligned}
\Delta E & =E_{O_{2}}^{\prime}-E_{O_{2}}^{\prime \prime}=0.0147 \log \frac{a_{O_{2}}^{\prime}}{a_{O_{2}}^{\prime \prime}} \\
& -0.059\left(p H^{\prime}-p H^{\prime \prime}\right)+c \log \frac{a_{t}^{\prime}}{a_{t}^{\prime \prime}}
\end{aligned}
$$

Our electrochemical study of two platinum electrodes, implanted at 5 meters height difference in a lime tree stem yielded significant solar energy induced potential differences. The first term of the calculated theoretical formula (eqn. 11) for the measured electrochemical potential difference is most important and shows that the recorded potential difference between the platinum electrodes at two positions at the lime tree is dependent on the respective oxygen concentrations. The second term in eqn. 11 may vanish when it is assumed that the $\mathrm{pH}$ of the xylem water is essentially the same at the two sites. But how we define and measure the $\mathrm{pH}$ value of tensile water? The third term considers the unknown chemical activity of tensile water. It is known to change along the tree stem with the height of the tree. Here, a new theory is needed to understand the activity of tensile water. But a simplified evaluation of eqn. 11 is possible on the basis of sap flow experiments performed on the same lime tree (Tilia cordata). Fig. 6 shows that sap flow density in the lime tree essentially parallels solar radiation distribution. From this it may be concluded that the sap driving water tension differ- 
ence may cease after solar irradiation ceases. However, Fig. 3 shows that when solar radiation approaches zero, the measured electrode potential difference is still near its maximum. It follows from this that, to a first approximation, we can neglect the third term, because $a_{\mathrm{t}}^{\prime}$ and $a^{\prime \prime}{ }_{\mathrm{t}}$ in the tree will be essentially identical, while there is still a significant electrochemical potential difference. Also the $\mathrm{pH}$ values, if they should depend on the tensile strength of water, will then be identical, which again justifies the omission of the second term. These are important considerations and mean that for the process studied (transport, turnover and concentration of oxygen) is not dependent on tensile water conditions. This was not evident at the beginning of theoretical considerations. Consequently, only the first term of eqn. 11 will remain important, leading to the following relation for the measured potential difference (in Volt) from the lime tree (eqn. 12):

$$
\Delta E=0.0147 \log \frac{a_{O_{2}^{\prime}}^{\prime}}{a_{O_{2}}^{\prime \prime}}
$$

Since $a_{\mathrm{O}_{2}}=\gamma c_{\mathrm{O}_{2}}$, the potential difference will essentially depend on the oxygen concentration difference, provided the proportionality coefficients $\gamma_{\mathrm{O}_{2}}^{\prime}$ and $\gamma^{\prime \prime}{ }_{\mathrm{O} 2}$ at positions with possible different tensile strength of water are identical. A last detail to be considered in this relation is the Nernst factor 0.0147 . Its calculation involved the consideration of the ambient temperature $T$ (compare eqn. 2 and eqn. 6 ), which in the case of eqn. 3, eqn. 7 and eqn. 12 was selected to be $25{ }^{\circ} \mathrm{C}$. Fig. 7 shows that the temperature during a sunny day did not vary more than $7{ }^{\circ} \mathrm{C}$. If the temperature would be lowered by such a value, the numerical factor of 0.0147 would just decrease to 0.0141 . This would mean that for an oxygen concentration difference of one order of magnitude $\left(\log _{10}=\right.$ 1) between the two electrodes the temperature dependent change would just amount to $6 \mathrm{mV}$. A look at Fig. 2 shows that $\Delta E$ values of $120 \mathrm{mV}$ have been measured. A temperature effect would, consequently, be smaller by a factor 20. However, for the electrochemical potential difference observed during the non-vegetative period of the lime tree (Fig. 4 and Fig. 5), which was up to $30 \mathrm{mV}$, the possible temperature effect may amount up to $20 \%$, if the two electrodes are exposed to the full temperature difference. However, only a small fraction of the temperature difference may expected to be present.

\section{Conclusion}

From the above considerations it may be concluded that the two platinum electrodes inserted into the water conducting tissue truly monitor the respective oxygen concentration in the xylem sap. In addition, the analyses indicate that trees remain metabolically active and their tissues may consume oxygen during winter time and respond to solar heating. The shape of the potential difference curves recorded for the lime tree during the vegetation period may qualitatively reflect the oxygen turnover.

More experience will be needed for a reliable interpretation and a suitable reference electrode should be developed for successful insertion into the xylem for quantitative measurements of the oxygen concentration dynamics at well-defined sites of the tree stem. The proposed measurement strategy may help to better evaluate oxygen turnover dynamics in tree stems. Furthermore, the potential variations observed indicate that oxygen concentrations in tree stems may vary up to 8 orders of magnitude. This clearly verifies that tree tissues experience periodic and dramatic oxygen deficiencies. These brief considerations already suggest that valuable information on the energetic state and dynamics of living trees is consequently to be expected from future experiments on the dynamics of oxygen supply in tree stems. An important experimental step towards electrochemically-based quantitative oxygen measurements in well-defined locations of the tree trunk is the development of a suitable reference electrode, generating a calibrated potential, which can safely be inserted into the xylem tissue.

\section{Acknowledgments}

We would like to thank the anonymous reviewer for his/her precious comments on the manuscript.

\section{References}

Burgdorf M (2006). Xylem-Saftfluss und Sauerstoffversorgung im Stamm von Betula pendula [Xylem sapflow and oxygen supply in the trunk of Betula pendula]. Mathematisch-Naturwissenschaftlichen Fakultät, Heinrich-Heine-Universität, Düsseldorf, Germany, pp. 205. [in German]

Cermák J, Kučera J, Bauerle WL, Phillips N, Hinckley TM (2007). Tree water storage and its diurnal dynamics related to sap flow and changes in stem volume in old-growth Douglasfir trees. Tree Physiology 27: 181-198. - doi: 10.1093/treephys/27.2.181

Del Hierro AM, Kronberger W, Hietz P, Offenthaler I, Richter $H$ (2002). A new method to determine the oxygen concentration inside the sapwood of trees. Journal of Experimental Botany 53: 559-563. - doi: 10.1093/jexbot $/ 53.36$ 8.559

Fensom DS (1963). The bioelectrical potentials of plants and their functional significance: $V$. Some daily and seasonal changes in the electical potential and resistance of living trees. Canadian Journal of Botany 41: 831-851. - doi: 10.1139/b63-068

Gansert D (2003). Xylem sap flow as a major pathway for oxygen supply to the sapwood of birch (Betula pubescens Ehr.). Plant, Cell and Environment 26: 1803-1814. - doi: 10.1046/j.13653040.2003.01097.x

Gibert D, Le Mouel J-L, Lambs L, Nicollin F, Per- rier $F$ (2006). Sap flow and daily electrical potential variations in a tree trunk. Plant Science 2006: 572-584. - doi: 10.1016/j.plantsci.2006.06. 012

Koppán A, Szarka L, Wetsztergom V (2000). Annual fluctuations in amplitudes of daily variations of electrical signals measured in the tree trunk of a standing tree. Comptes rendus de l'Académie des Sciences Paris 323: 559-563.

Koppán A, Fenyvesi A, Szarka L, Wesztergom V (2002). Measurement of electrical potential difference on trees. Acta Biologica Szegediensis 46: 37-38.

Milne R, Ford ED, Deans JD (1983). Time lags in the water relations of Sitka spruce. Forest Ecology and Management 5 (1): 1-25. - doi: 10.1016/ 0378-1127(83)90065-8

Morat P, Le Mouel J-L, Grenier A (1994). Electrical potential on a tree. A measurement of the sap flow? Comptes rendus de l'Académie des Sciences Paris 317: 98-101. [online] URL: http:// cat.inist.fr/?aModele=afficheN\&cpsidt $=3983978$ Nadezhdina N, Cermák J, Nadezhdin V (1998). Heat field deformation method for sap flow measurements. In: Proceedings of the $4^{\text {th }}$ International Workshop "Measuring Sap Flow in Intact Plants" (Cermák J, Nadezhdina N eds). IUFRO Publications, Brno, Czech Republic, Publishing House of Mendel University, Zidlochovice, Czech Republic, pp. 72-92.

Nadezhdina N, Tributsch H, Cermak J (2004). Infra-red images of heat field around a linear heater and sap flow in stems of lime trees under natural and experimental conditions. Annals of Forest Science 61: 203-213. - doi: 10.1051/forest:2004014

Nadezhdina N, Vandegehuchte MW, Steppe K (2012). Sap flux density measurements based on the heat field deformation method. Trees 26: 1439-1448. - doi: 10.1007/s00468-012-0718-3 Schulze E-D, Cermák J, Matyssek M, Penka M, Zimmermann R, Vasícek F, Gries W, Kucera J (2004). Canopy transpiration and water fluxes in the xylem of the trunk of Larix and Picea trees - a comparison of xylem flow, porometer and cuvette measurements. Oecologia 66: 475483. - doi: 10.1007/BF00379337

Sevanto S, Vesala T, Perämäki M, Nikinmaa E (2002). Time lags for xylem and stem diameter variations in a Scots pine tree. Plant, Cell and Environment 25: 1071-1077. - doi: 10.1046/j.13653040.2002.00884.X

Sortz J, Hietz P (2006). Gas diffusion through wood: implication for oxygen supply. Trees 20: 34-41. - doi: 10.1007/s00468-005-0010-x

Spicer R, Holbrook NM (2005). Within-stem oxygen concentration and sap flow in four temperate tree species: does long-lived xylem parenchyma experience hypoxia? Plant, Cell and Environment 28: 192-201. - doi: 10.1111/j.1365-3040.20 04.01262.x

Szabó N, Tötzke C, Tributsch H (2008). Total internal reflectance-infrared structural studies on tensile water formation during evaporation from nanopores.The Journal of Physical Chemistry A 112 (28): 6313-6319. - doi: 10.1021/jp80 38479

Toriyama H (1991). Individuality in the anomalous bioelectrical potential of silk tees prior to earth quakes. Science Reports of Tokyo Woman's Christian University 90-94: 1067-1077. 
Tributsch H, Cermak J, Nadezhdina N (2005). Kinetic Studies on the Tensile State of Water in Trees. The Journal of Physical Chemistry B 109: 17693-17707. - doi: 10.1021/jpo51242u Wronski EB, Holmes JW, Turner NC (1985). Phase and amplitude relations between transpiration, water potential and stem shrinkage. Plant, Cell and Environment 8: 613-622. - doi: 10.1111/j.13653040.1985.tbo1700.x

Zweifel R, Häsler R (2001). Dynamics of water storage in mature subalpine Picea abies: temporal and spatial patterns of change in stem radius. Tree Physiology 21: 561-569. - doi: 10.1093/treephys/21.9.561 